\title{
TRABALHO: HORIZONTE 2021
}

\author{
GaUdênCIO FrigotTo*
}

A

o longo do processo histórico produzem-se relações sociais que engendram contradições que conduzem a um salto qualitativo no modo dos seres humanos produzirem sua existência na sociedade. Assim foi a passagem do modo de produção antigo para a sociedade feudal e desta para o atual modo de produção capitalista. Do mesmo modo, mudanças qualitativas na base científico-técnica na produção, dentro das mesmas relaçôes sociais classistas, conduzem, ao mesmo tempo, a possibilidades ampliadas de exploração e a contradições mais agudas que indicam a necessidade de superação deste modo de produção.

Com Karl Marx aprendemos que os modos de produção classistas engendram, em sua estrutura constitutiva, um metabolismo em que as determinações básicas que os dinamizam são contraditórias e se constituem em obstáculo e os conduzem a crises e desenvolvimento de forças sociais que, em dado momento, os implodem. Assim, a escravidão e o servilismo foram o dinamismo dos modos de produção pré-capitalistas e, em dado momento, obstáculos e geradores na determinação de suas crises e de sua superação.

O modo de produção capitalista, por não superar a estrutura de classes, tem na contradição entre a exponencial capacidade e a necessidade de desenvolver forças produtivas, armas para aumentar a exploração da classe trabalhadora e a concentração de capital, mas, ao mesmo tempo, a incapacidade de socializar a produção fruto do trabalho. Contradição que o conduziu a revoltas, guerras por disputa de poder e mercados e, também, revoluçóes socialistas.

Depois de mais de dois séculos de vigência hegemônica do sistema capitalista de produção social vivemos, por combinação de determinações históricas, num contexto onde o sistema capital esgrima sua violência e vingança sem disfarce

\footnotetext{
* Resenha do livro CATTANI, Antônio David (Org.). Trabalho: Horizonte 2021, Porto Alegre: Editora Escritos, 2014.

** Universidade Federal Fluminense (UFF). Universidade do Estado do Rio de Janeiro (UERJ), Programa de Pós-graduação em Políticas Públicas e Formação Humana. Rio de Janeiro, RJ. Brasil. E-mail de contato: gfrigotto@globo.com
} 
sobre a classe trabalhadora impondo-lhes a ampliação do desemprego estrutural e a super-exploraçáo e perda dos direitos duramente conquistados.

Esta combinação histórica tem, de um lado, a apropriação privada da ciência e, sob a base desta, o salto tecnológico que une microeletrônica e informação que modifica a maneira de operar com a matéria e os processos de produção e gestáo do trabalho humano e, por outro lado, o colapso do socialismo real. Os efeitos sobre a classe trabalhadora - em suas condiçóes de trabalho e de sua organização - foram explosivos e potencializam o que Marx observara em meados do século XIX.

A máquina, triunfo do ser humano sobre as forças naturais, converte-se, nas mãos dos capitalistas, em instrumento de servidão de seres humanos a estas mesmas forças [...]; a máquina, meio infalível para encurtar o trabalho cotidiano, prolonga-o, nas mãos do capitalista [...]; a máquina, varinha de condão para aumentar a riqueza do produtor, empobrece-o em mãos.do capitalista (MARX, apud PARIS, 2002, p. 235)

No âmbito das relaçóes internacionais de poder, o colapso do socialismo real dá às forças do capital a chave para decretar o retorno às teses ultraconservadoras de que o capitalismo se constitui numa sociedade de tipo natural, por supostamente corresponder ao que é a natureza humana: a busca do bem individual próprio, o egoísmo produtivo. Doutrina esta que, no plano do pensamento crítico, paradoxalmente, assumiu o termo de neoliberalismo. Talvez, a denominação mais adequada fosse a de neoconservadorismo ou de ultraconservadorismo.

Com efeito, o pensamento de Friedrich Hayek, cuja tese central em seu livro O Caminho da Servidão (1987), é de que as políticas públicas que visam diminuir a desigualdade social conduzem à servidão e o livre mercado conduz à prosperidade, serviu de base às políticas ultraconservadoras que assolam o mundo desde meados da década de 1970. Duas palavras sintetizam o pesadelo da classe trabalhadora, austeridade nos países da comunidade europeia e ajuste nos países de capitalismo dependente, pois elas expressam uma permanente e crescente perda de direitos.

Um conjunto de obras de abrangência diversa e de campos disciplinares distintos já em seus títulos sinalizam os efeitos das políticas neoconservadoras para a classe trabalhadora. Viviane Forrester, em O horror econômico (1999), explicita os efeitos destas políticas sobre a classe trabalhadora perguntando-se se seria a busca, todos os dias da semana e por muitos meses, do emprego uma forma de emprego. Danièle Linhart (2007) explicita para a França esta mesma realidade dando como título de um de seus livros: $A$ desmedida do Capital. Richard Sennett (1999) em A corrosão do caráter e Christophe Dejours (2001) em A banalização da injustiça 
social explicitam os efeitos sobre as pessoas e sua subjetividade vivendo o dia a dia de suas vidas em suspenso, sem poder programar o amanhã e o médio e longo prazos. István Mészáros, em $O$ desafio e o fardo do tempo histórico, indica os efeitos da crise do sistema capital na destruição de direitos e das bases da vida e seu caráter cada vez mais irracional.

Esta realidade é hoje regressiva e perversa, mesmo em sociedades que efetivaram a revolução burguesa na sua forma clássica e que, no contexto do Estado de Bem-estar Social, não eliminaram a desigualdade, mas superaram a pobreza extrema. Em países, entretanto, como o Brasil, onde sua classe dominante incorporou o estigma do colonizador e dos escravocratas, os níveis de desigualdade, mesmo tendo diminuído a extrema miséria, os efeitos são mais perversos.

O conjunto de artigos que compóe a coletânea organizada por Antônio David Cattani, com o sugestivo título Trabalho: Horizonte 2021, explicita o tempo histórico em que vivemos sob o sistema capital e as consequências sobre o trabalho e o seu futuro. Os textos analisam o trabalho sob diferentes aspectos e tomam como demarcação temporal de início, a segunda metade da década de 1970 onde se potencializou a força do capital pela combinação da apropriação privada do novo salto tecnológico e, de forma mais concentrada, o colapso, mas não o fracasso, do socialismo real. Não fracasso, pois demarcou o século XX no contraponto à desmedida do capital e legou para a história um duplo aprendizado: a possibilidade de não repetir os erros e a de dilatar os acertos. Como horizonte de maturação e, talvez, de esgotamento e acirramento das contradiçôes do sistema capital e possíveis desfechos, demarcam o ano de 2021.

O sentido que assumirá este tempo de ebulição não está determinado, apenas serve como horizonte hipotético. Uma posição que emana da opção teórica dos textos da coletânea na qual não cabem determinismos. Como nos ensina Florestan Fernandes: "[...] a história nunca se fecha por si mesma e nunca se fecha para sempre. São os homens, em grupos e confrontando-se como classes em conflito, que 'fecham' ou 'abrem' os circuitos da história." (FERNANDES, 1997, p. 5)

Para o leitor atento, que caminha dentro da mesma direção de análise e com a preocupação de buscar novas relaçóes sociais, de superação da violência de classe, perceberá que o que está subjacente ao conjunto da coletânea é a questão central colocada pelo historiador Eric Hobsbawm que define o problema central que nos interpela a uma resposta no século XXI para que a humanidade tenha horizonte de futuro:

Se pensarmos em termos de como "os homens fazem a própria história”, a grande questão é a seguinte: historicamente comunidades e sistemas sociais buscam a estabilização e a reprodução criando mecanismos contra saltos perturbadores no desconhe- 
cido. Como, então, humanos e sociedades estruturados para resistir a transformaçóes dinâmicas se adaptam a um modo de produção cuja essência é o desenvolvimento dinâmico interminável e imprevisível? (HOBSBAWM, 2010, p. 4)

Sendo o trabalho a atividade vital, necessária e imprescindível, na produção e reprodução material do ser humano, as forças dominantes que o organizam incidem sobre o que Engels definiu como leis primeira e segunda do processo histórico do legado de Marx. A lei primeira:

O simples fato, escondido sobre crescente manto ideológico, de que os homens necessitam, antes de tudo, comida, bebida, moradia e vestuário, antes de poderem praticar a política, ciência, arte, religiấo, etc.; que, portanto, a produção imediata de víveres e com isso o correspondente estágio econômico de um povo ou de uma época constitui o fundamento a parir do qual as instituiçôes políticas, as instituiçóes jurídicas, a arte e mesmo as noçôes religiosas do povo em questão se desenvolve, na ordem em elas devem ser explicadas - e não ao contrário como nós até então fazíamos [...]. (ENGELS, 1883, p. 1)

A segunda é a lei da mais-valia, mediante a qual o capital expropria do trabalhador parte do tempo que não lhe é pago, pois o capitalista, por contrato, é que o administra. Pela crescente incorporação do conhecimento científico-técnico (capital morto) que substitui capital vivo - força de trabalho -, a tendência é de um aumento cada vez maior de desemprego estrutural planetariamente e a emergência das mais diversas formas de trabalho precário. $\mathrm{O}$ que a coletânea nos traz é, ao mesmo tempo, este processo irracional, acelerado e violento do capital sobre o trabalho que degrada e mutila, física, psíquica e emocionalmente, milhões de trabalhadores, mas também suas contradiçóes e indícios de novas formas de economia e produção solidárias.

Uma coletânea fundamental para ser lida e debatida por todos aqueles que entendem, como o historiador Eric Hobsbawm, que as pessoas não foram criadas para viverem sob o capitalismo e, por isso, o socialismo continua na agenda. Uma coletânea que, por filiar-se ao método histórico-dialético, engendra três dimensóes indissociáveis e fundamentais para o campo crítico atualmente.

Primeira, por um esforço de pesquisa e de análise que revele o que está subjacente as diferentes dimensôes da produção da vida humana onde o trabalho tem centralidade. Isto não por ser superior as demais atividades humanas. Pelo contrário, por ser este uma necessidade imperativa à condição de sermos um ser, a um tempo da natureza em geral e diferente dela e que se reproduz materialmente metabolizando-a e transformando-a. 
Em segundo lugar, por entender que é fundamental compreender como se produz a realidade humana atual sob o capitalismo, como Cattani finaliza a apresentação da coletânea,

[...] longe de serem orientados por um espírito contemplativo e desinteressado, os textos se inserem no esforço coletivo de entendimento das situaçóes que condicionam e limitam o presente, tendo como horizonte as condiçóes econômicas e sociais que podem construir o bem comum. (p. 10)

Por fim, na construção prática destas condições de construir relações sociais, econômicas, políticas, educacionais e culturais que concorram para o bem comum na direção da utopia de superação do sistema capitalista, a travessia implica açôes e políticas que não se radicam no voluntarismo mas na dialética do velho e do novo buscando mudanças, mesmo que dentro da ordem do capital, mas contra esta ordem. Sem estas mudanças, como aponta Harvey, quem mais sofreriam são os pobres. Isto não elide, pelo contrário, implica contrapor-se à propriedade e ao trabalho como valores de troca e recuperar ambos como valores de um

[...] mundo alternativo e mundo no qual se oferecem valores de uso. Assim podemos nos concentra nos valores de uso e tentar reduzir o papel dos valores de troca. [...] Pode-se imaginar a direção na qual se moverá uma alternativa socialista, se nos afastarmos da forma dominante de acumulaçáo de capital que hoje comanda tudo. (HARVEY, 2013, p. 3-4)

\section{Referências}

DEJOURS, C. A banalização da injustiça social. Rio de Janeiro: Fundação Getúlio Vargas, 2001.

ENGELS, F. Discurso diante do túmulo de Karl Marx proferido no cemitério de Highgate, em 17 de março de 1883. Revista Iskra, Disponível em: < https://revistaiskra.wordpress. com>. Acesso em 05.07.2013.

FERNANDES, F. Os circuitos da história. São Paulo: HUCITEC, 1977.

FORRESTER, V. O horror econômico. São Paulo: Editora da UNESP, 1999.

HARVEY, D. A importância da Imaginação pós-capitalista. 2013. Entrevista a Ronan Burtenshaw e Aubrey Robinson. Disponível em: <https://www.irishleftreview.org $>$. Tradução de Vila Vadu.

HAYEK, F. O caminho da Servidão. Rio de Janeiro: Instituto Liberal, 1987. 
HOBSBAWM, E. Política extrema. Folha de Sáo Paulo, São Paulo, 18 abr. 2010. Caderno Mais, p, 4-6.

LINHART, D. A desmedida do capital. São Paulo: Boitempo, 2007.

MÉSZÁROS, I. O desafio e o fardo do tempo histórico. São Paulo: Boitempo, 2007.

PARIS, C. O animal Cultural. São Carlos: Editora da UFSCar, 2002.

SENNETT, R. A corrosão do caráter. Rio de Janeiro: Record, 1999.

Recebido em 15 de julho de 2015.

Aprovado em 26 de agosto de 2015.

DOI: http://dx.doi.org/10.1590/ES0101-73302015156426 